\title{
Relationship between the fractal dimension anisotropy of the spatial faults distribution and the paleostress fields on a Variscan granitic massif (Central Spain): the $F$-parameter
}

\author{
R. Pérez-López ${ }^{\mathrm{a}, *}$, C. Paredes ${ }^{\mathrm{b}}$, A. Muñoz-Martín ${ }^{\mathrm{c}}$ \\ ${ }^{a}$ Dpto. de Ciencias Ambientales y Recursos Naturales, Facultad de Farmacia, Universidad San Pablo—CEU, Campus Montepríncipe, Ctra Boadilla del \\ Monte km 5.3, Boadilla del Monte, Madrid 28688, Spain \\ ${ }^{\mathrm{b}}$ Dpto. de Matemática Aplicada y Métodos Informáticos, Escuela Técnica Superior de Ingenieros de Minas, Universidad Politécnica de Madrid, C/Alenza 4, \\ Madrid 28003, Spain \\ ${ }^{c}$ Dpto. de Geodinámica, Facultad de Ciencias Geológicas, Universidad Complutense de Madrid, Avda. Complutense s/n, Madrid 28040, Spain
}

Received 29 June 2004

Available online 8 March 2005

\begin{abstract}
The spatial distribution of faults is usually described as a fractal set characterised by the fractal dimension. In this work, we have filtered fault patterns interpreted from digital elevation models, aerial photographs and field maps, by using structural geological parameters of the stress ellipsoid (stress tensor direction and stress ratio $R^{\prime}$ ) and age of deformation. From these filtered structural maps, we have obtained the fractal dimension associated with the fracture patterns developed during Permo-Triassic and Alpine tectonic events on a Variscan granitic massif located in the Spanish Central System. Oriented fractal dimensions were calculated on several transects crossing the fault-filtered maps. The fractal dimension $(D)$, calculated by 1-D box-counting, describes an ellipse on a polar plot with the short axis as the minimum value $\left(D_{\mathrm{Hmin}}\right)$ and the long axis as the maximum value $\left(D_{\mathrm{Hmax}}\right)$ of the fractal dimensions measured. From these analyses, we have defined the $F$-parameter as a function of the maximum value, minimum value and vertical value of fractal dimension $\left(D_{\mathrm{z}}\right), F=\left(D_{\mathrm{z}}-D_{\mathrm{Hmin}}\right) /\left(D_{\mathrm{Hmax}}-\right.$ $\left.D_{\text {Hmin }}\right)$. Finally we have established, from a local scale analysis, a perpendicular relationship between the principal axes of the ellipse of the fractal spatial anisotropy of fractures and the principal axes of the stress tensor $\left(\sigma_{\mathrm{Hmax}}, \sigma_{\mathrm{Hmin}}\right.$ and $\left.\sigma_{\mathrm{z}}\right)$ that generates this dynamic pattern of fractures. Furthermore, the $F$-parameter and the stress ratio $R^{\prime}$ are equivalents and, applied in this area, both show a triaxial extension. (C) 2005 Elsevier Ltd. All rights reserved.
\end{abstract}

Keywords: Fractal; Anisotropy; Stress tensor; F-parameter; Spanish Central System

\section{Introduction and objectives}

The spatial distribution of faults is commonly represented by structural maps of fracture traces interpreted from aerial photographs, digital elevation models (DEMs) and field geological mapping. Structural geologists use these maps in order to establish the main orientation sets and the longest faults at this scale. These fracture sets are related to the stress regime and geological setting and are

\footnotetext{
* Corresponding author. Tel.: +1-34-913724765; fax: +1-34913510496

E-mail addresses: rperez.fcex@ceu.es (R. Pérez-López), cparedes@ dmami.upm.es (C. Paredes), amunoz@geo.ucm.es (A. Muñoz-Martín).
}

0191-8141/\$ - see front matter (C) 2005 Elsevier Ltd. All rights reserved. doi:10.1016/j.jsg.2005.01.002 interpreted in terms of kinematics and dynamics. To the present time, these maps represent a long time interval, with overlapping fault patterns due to several stress regimes evolving through geological time. The patterns of reactivated and newly formed fault sets in a particular region can be identified using several techniques such as cartography, geochronological dating and stress inversion (Angelier, 1979; Etchecopar et al., 1981; Reches, 1992; De Vicente et al., 1996). Therefore, it is possible to obtain meso-scale fracture patterns active during different tectonic events.

At the present time, DEMs are a powerful and useful tool for the geologist to map morphological lineaments on the topography at several scales (Mark and Goodchild, 1986). These lineaments are easily interpreted using shaded relief digital terrain maps. However, it is highly recommended that these structural maps be compared with aerial photographs and satellite orthoimages in the same zone. 
Otherwise, errors could be incorporated into the structural map and subsequent analyses will be spurious or biased (Pérez-López et al., 2000). In this work, three DEMs were constructed and analysed as a function of pixel size: 2, 10 and $500 \mathrm{~m}$ from topographic maps at 1:2000, 1:10,000 and 1:500,000 scale, respectively.

The main goal of this paper is to establish the relationship between the fractal geometry of the spatial fault distribution and the stress field. In order to reach this objective, we have carried out statistical analysis on remote-sensing derived fault data from Variscan granite of the Spanish Central System (SCS). In particular: (1) we have mapped the fracturing in an area from lineament interpretation of DEMs, aerial photographic interpretation, taking measures of strike and dip of fractures from field work and applying fault population analyses to describe the paleostress field; (2) we have measured the fractal dimension $(D)$ of these fracture maps by box-counting. From this relationship, it is possible to define a geometric fractal factor $(F)$ conditioned by the tectonic regime as shown in the discussion.

Previously, the spatial fault distribution was described as a fractal set, where the fractal dimension $(D)$ is obtained by the box-counting technique (Velde et al., 1990; Gillespie et al., 1993; Walsh and Watterson, 1993; Barton and La Pointe, 1995; Castaing et al., 1996; Rodríguez-Pascua et al., 2003). The so-called box-dimension, $D$, represents the fractality or complexity degree of the spatial distribution of the fractal geometry measured (Hasting and Sugihara, 1993). The fractal character of the fault sets indicates that there is a non-characteristic spatial length and the structural maps show the same complexity at several scales. The statistical spatial relations between faults are the same at several scales. From this idea it is possible to argue that there is a scale range where statistical properties of the fracture sets are linked to the tectonic stress and strain conditions. This scaling is only valid between two scale limits: the inner and outer cut-offs, because of the limited resolution of fracture sets and the finite sampling window, respectively.

If the spatial distribution of faults is controlled by a particular tectonic stress regime, then the complexity value defined by the fractality will be related to the tectonic stress field by geometrical parameters. However, the spatial fault distribution in an area is formed by several fracture patterns as a consequence of several stress fields actuating on this area over time. For this reason, we have analysed several structural maps from DEMs, aerial photographs at 1:18,000 and 1:33,000 scale (Spanish and American aerial photographs) and Landsat regional orthoimages. The next step consists of describing the tectonic events that have been active in the studied area, using field data. From this analysis, two tectonic events were recognized in the studied area and, consequently, two dynamic structural maps were drawn at scale 1:10,000. The first tectonic event was dated

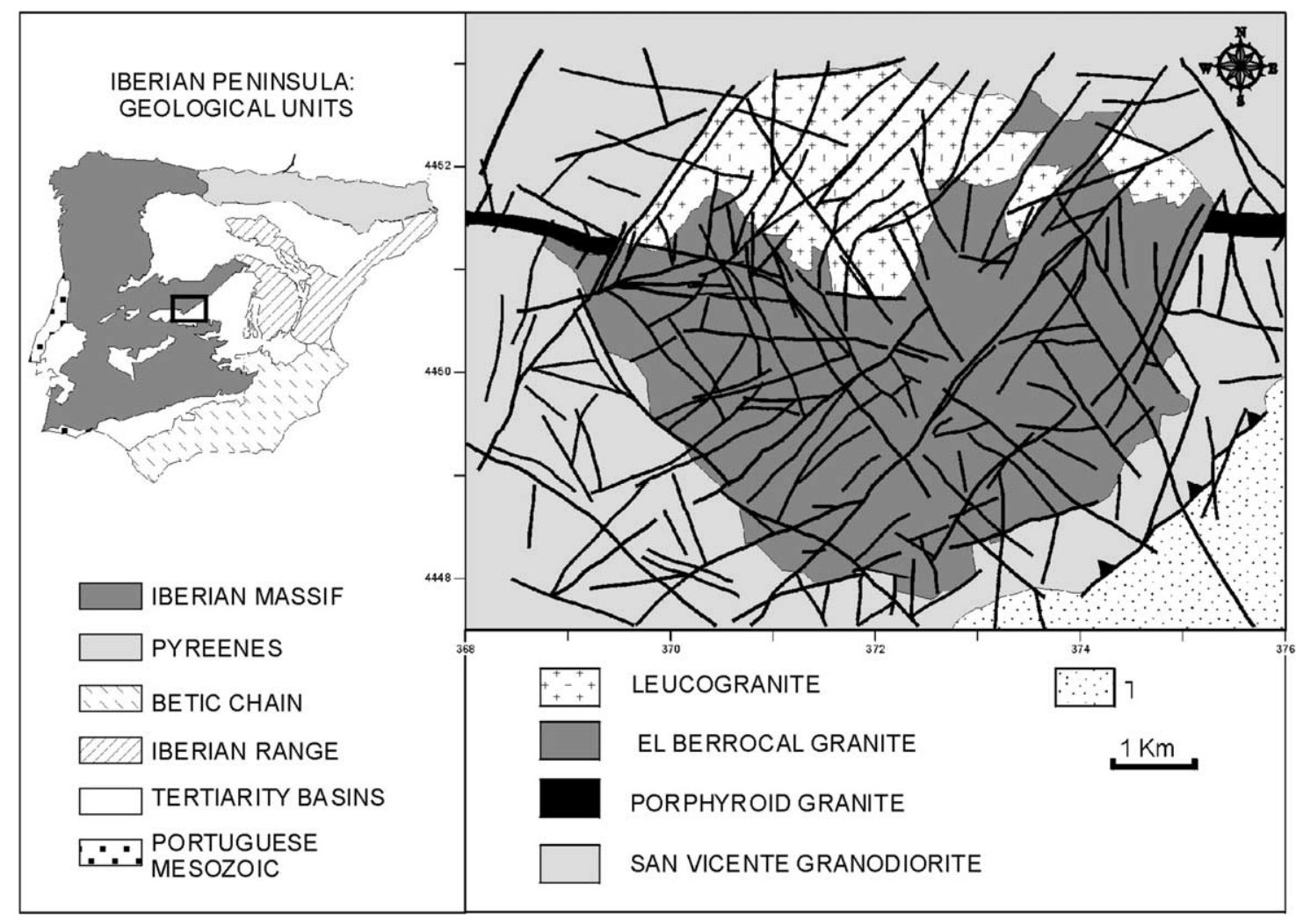

Fig. 1. (left) Geological synthesis sketch and (right) geographical location of the El Berrocal granitic massif. On the petrological sketch we can see the plots of the fractures interpreted from geological maps, digital terrain models (DEM), aerial photographs and field trips. 
at Lower Permian age and the second event from Eocene to Present.

The second part of this paper addresses the fractal geometry of these maps, calculating the fractal dimension by the inverse box-counting technique (Paredes and Elorza, 1999). From both analyses, we can link a fractal value to the interpreted tectonic events using geometrical parameters.
This analysis was performed on 'El Berrocal', a massif of granite located in the Spanish Central System Range (central Spain), and the area was selected for several reasons: (1) the granites are homogeneous and (2) this granite does not have bedding discontinuities that control the development of particular fracture directions. Moreover, several geological and topographical data sets are available

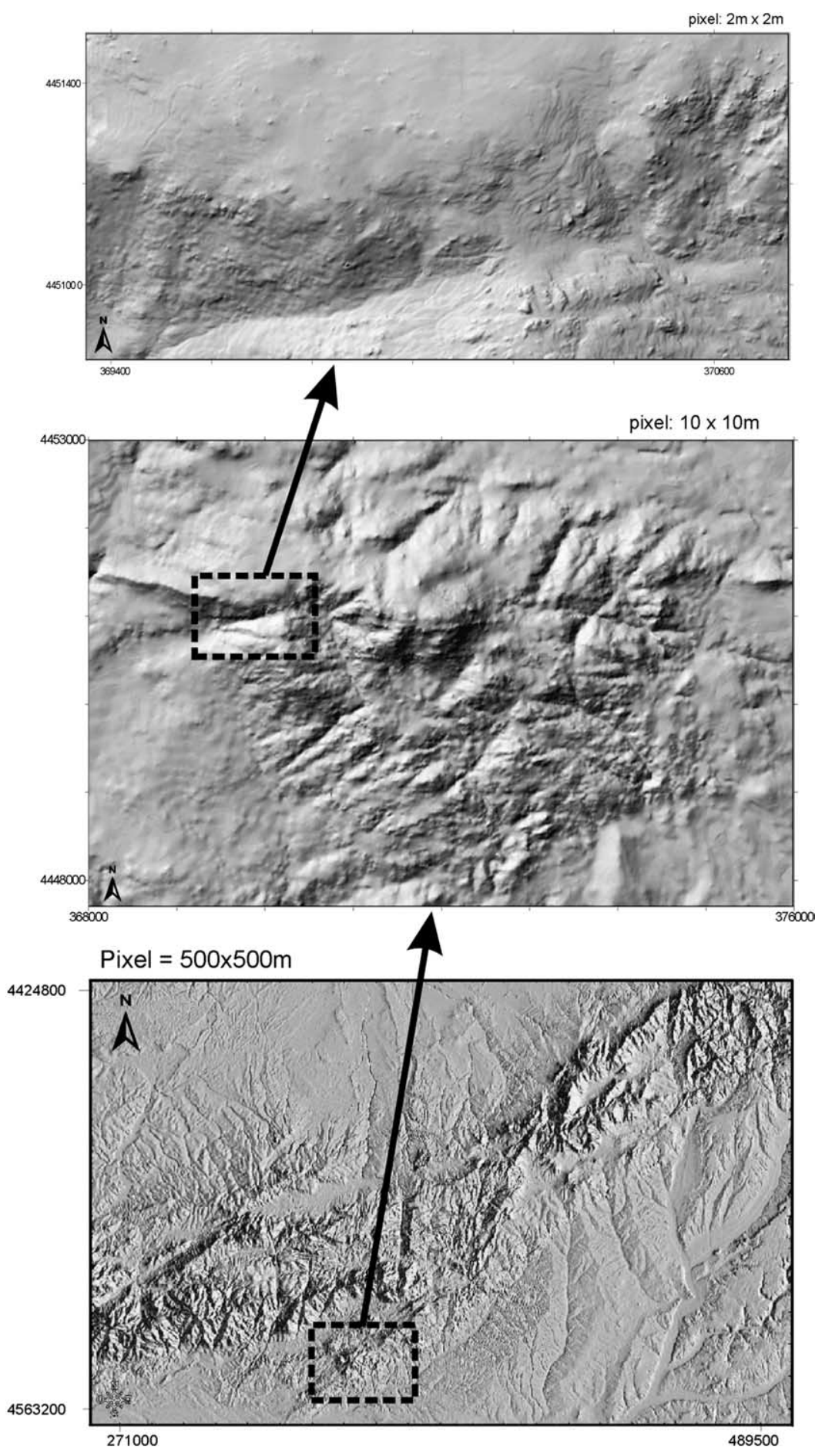

Fig. 2. Shadowed terrain models at pixel size $500 \times 500 \mathrm{~m}$ (upper), $10 \times 10 \mathrm{~m}$ (centre) and $2 \times 2 \mathrm{~m}$ (lower), obtained from source topographical maps at scales of 1:500,000, 1:10,000 and 1:2000, respectively. 
in this area: aerial photographs, geological and topographical maps at several scales, boreholes, petrological and geochemical data, geochronological ages, etc. (Hidrobap Project, 1999)

\section{Geological and tectonic settings}

The granitic massif analysed, 'El Berrocal', is located within the Gredos Mountain Range and has an approximate surface area of $22 \mathrm{~km}^{2}$. This massif is part of the southern border of the SCS (Fig. 1). The SCS produces a NE-SW structural relief that divides two continental basins developed during the Tertiary from the Duero basin to the north and the Tajo basin to the south (De Vicente et al., 2004). The age of the oldest rocks of the SCS ranges from Precambrian to Upper Palaeozoic and they were affected by several tectonic and metamorphic events during the Caledonian and
Variscan orogeny (Capote et al., 1990). The Variscan basement has a thin cover of Cretaceous and Palaeogene rocks deformed during the Alpine Orogeny (TertiaryPresent) (De Vicente et al., 2004).

The lithology of the El Berrocal stock consists of quartz granites with alkali-feldspars, muscovite and biotite emplaced within a granodiorite body. The petrological facies are coarse leucogranites. There is a characteristic vertical dyke of aplitic granite, crossed by the massif (Fig. 1) and trending $\mathrm{E}-\mathrm{W}$.

The massif El Berrocal has been affected by the Hercynian (later stage) and Alpine orogeny. The Hercynian tectonic phase (Variscan deformation) recognized in the Iberian Peninsula is divided into two different stages: (1) extensional collapse under a strike-slip regime (vertical $\sigma_{2}$ ) and (2) extensional tectonics from relaxation during the ending phase of the Variscan deformation (González-Casado et al., 1996). The age of the granitic massif is $296.8 \pm 1 \mathrm{Ma}$,

\section{E:1:500.000. 1500 LINEAMENTS}

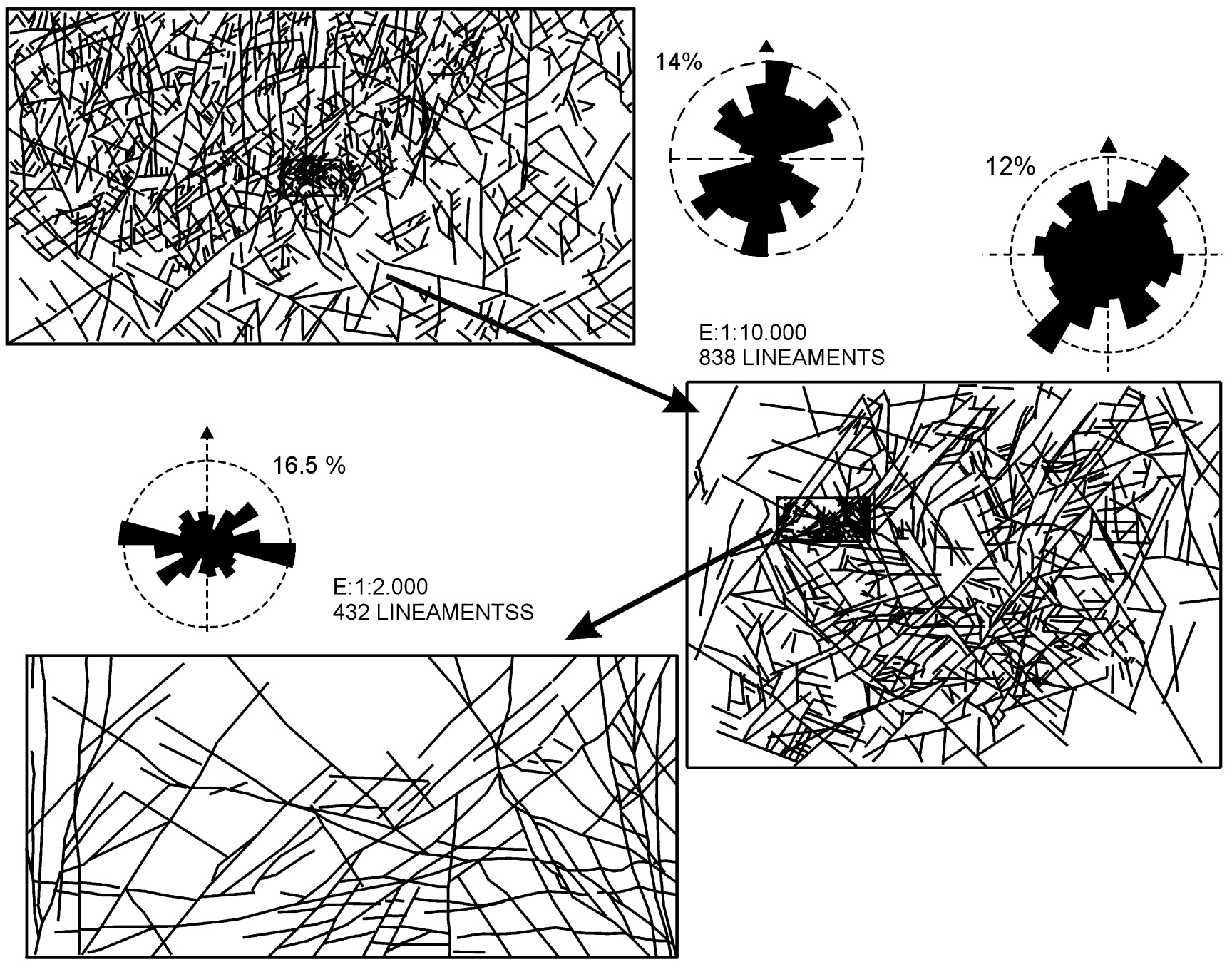

Fig. 3. Morphological lineaments interpreted from digital elevation models (DEM) of Fig. 2. Associated rose diagrams of frequency and longest sets are showed. These structural maps are represented at scales of 1:500,000 (upper), 1:10,000 (centre) and 1:2000 (lower). 
dated by $\mathrm{Rb} / \mathrm{Sr}$ techniques (Campos et al., 1996) and it was emplaced during the $\mathrm{N}-\mathrm{S}$ extension of Central Iberia, developed along the later Hercynian tectonic phase (Lower Permian) (Casquet et al., 1988).

The Alpine orogeny is affected by the SCS by a strikeslip stress field (Capote et al., 1990) because of the relative movement between the Iberian and Eurasian Plates (Vegas et al., 1990). The geological evolution during this orogeny is strongly influenced by the stress transmission from the active borders of the Iberian Peninsula. There are two tectonic episodes (De Vicente et al., 2004): The Pyrenees phase, with $\mathrm{N}-\mathrm{S}$ compression acting from Eocene to Oligocene and the Betics phase, with NW-SE compression from Miocene to Present (Muñoz-Martín et al., 1998). Both events activated E-W to ENE-WSW thrust faults as well as sinistral N-S and dextral NW-SE strike-slip faults under a strike-slip stress regime in Central Iberia (De Vicente et al., 2004). The Alpine structures measured in El Berrocal during the field work correspond to conjugate strike-slip faults oriented NW-SE and NNE-SSW and normal faults and dykes oriented NNW-SSE.

\section{Structural fault map at scale $1: 10,000$}

From three topographic maps $(1: 2000,1: 10,000$ and 1:500,000; Hidrobap Project, 1999), three DEMs were constructed (Fig. 2) to generate analytic shaded models from several illumination orientations. These models were used to identify morphological discontinuities. The DEMs were then included in a GIS designed for adding geological and topographical information.
From DEMs, aerial photographs (1:18,000 and 1:33,000) and geological cartography, three structural maps of fractures were drawn (Fig. 3). The average fracture strike orientation is NE-SW for 1:10,000 and 1:500,000 scale, whereas at a local scale (1:2000), the average fracture strike orientation is E-W. These lineaments are also well recognized in clastic sediments south of the area, in the Tertiary deposits of the Tajo basin.

The 1:2000 structural map shows 432 fractures whilst the 1:10,000 map includes 838 fractures. The structural map at scale 1:10,000 covers the entire massif and includes Tertiary sediments to the south. For this reason, the 1:10,000 scale map was selected to be filtered according to the stress fields interpreted.

Field data of fractures, faults and quartz dykes were measured inside of the granitic massif (Table 1).

\subsection{Stress inversion analysis}

The stress inversion method applied in order to obtain the paleostress tensor acting in El Berrocal was developed by Reches $(1987,1992)$. The $\sigma_{\text {Hmax }}$ trajectories were mapped following Lee and Angelier (1994). The inversion technique is based on the Navier-Coulomb fault criteria and the Bott equation (Bott, 1959) and the results obtained are the principal stress axes: $\sigma_{1}, \sigma_{2}$ and $\sigma_{3}$, the friction coefficient $(\mu)$ and the stress ratio $\left(R^{\prime}\right)$.

The stress ellipsoid is defined by the expression:

$$
R^{\prime}=\frac{\sigma_{\mathrm{z}}-\sigma_{\mathrm{x}}}{\sigma_{\mathrm{y}}-\sigma_{\mathrm{x}}}
$$

$R^{\prime}$ represents the stress ratio of the ellipsoid where $\sigma_{\mathrm{x}}$ is the

Table 1

Field measurements and geometric character of fault families in the El Berrocal granitic massif. The stereogram shows at a glance the main orientation of the structures observed and their character as normal and strike-slip faults. These structures were activated during the tectonic stages described in the text

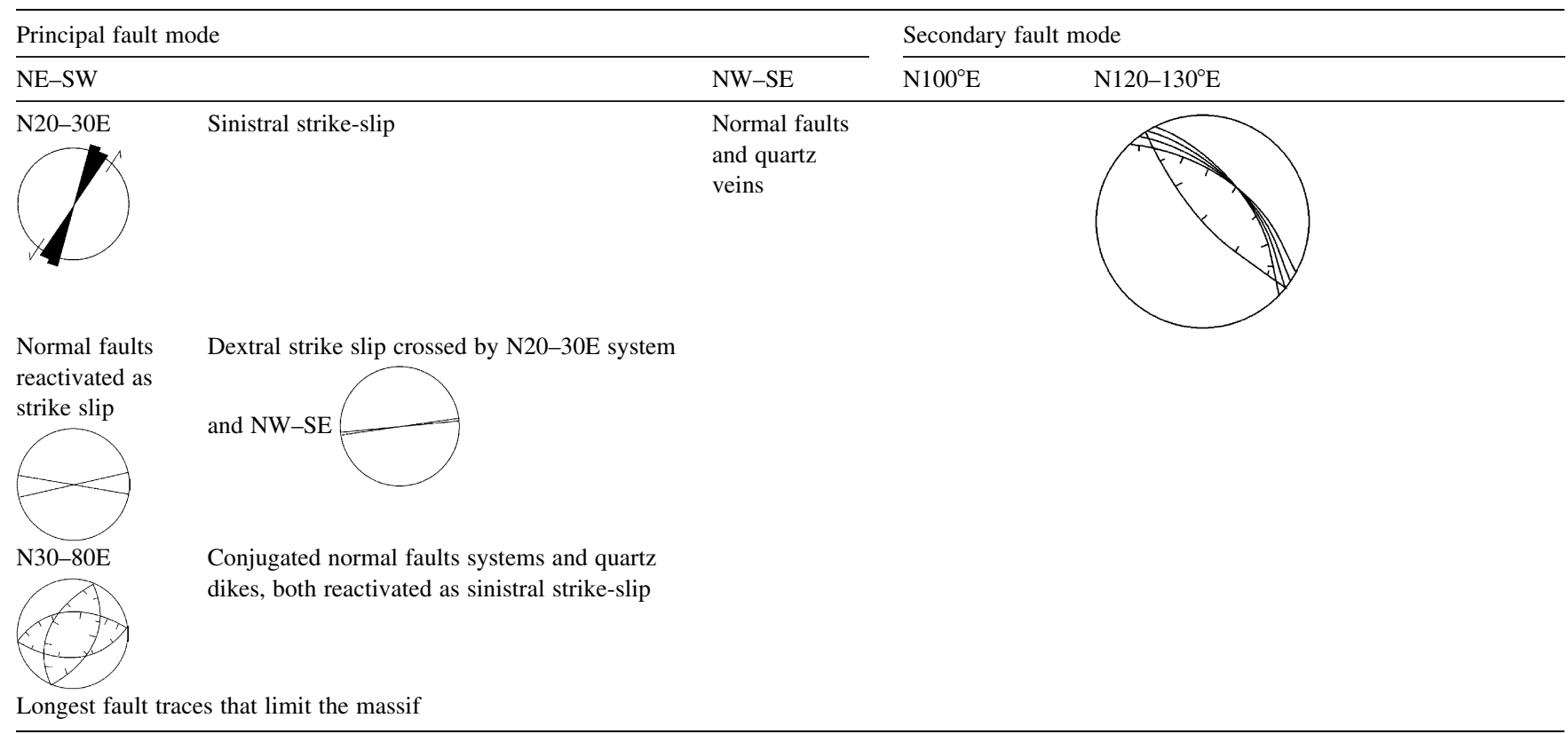




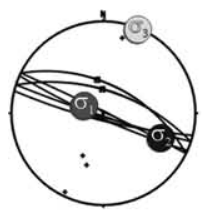

S50E

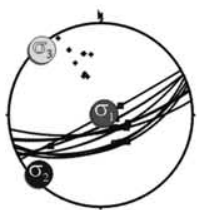

S51-52E

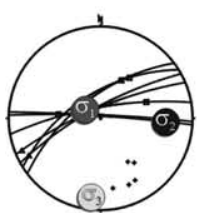

S59-60

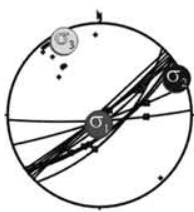

S28A

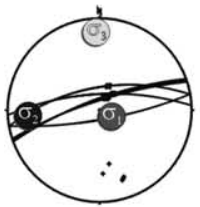

S62A

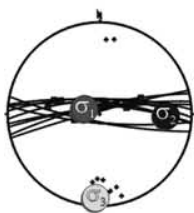

S26A

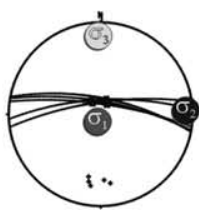

S2-3DA

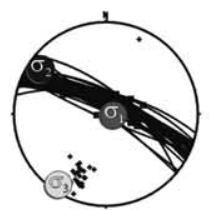

S69A

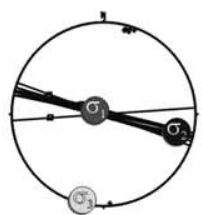

S75DA

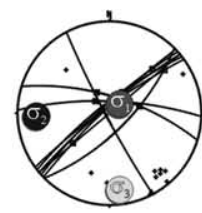

S115M

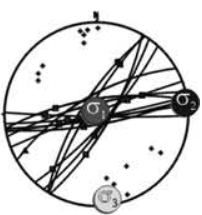

S84M

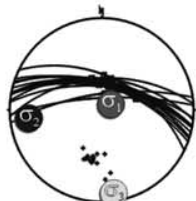

S101T

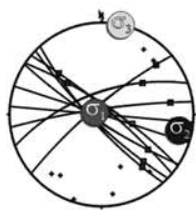

SR6A

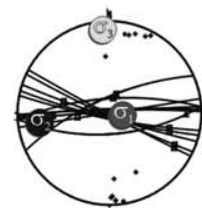

SR2A

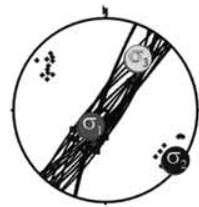

S110T

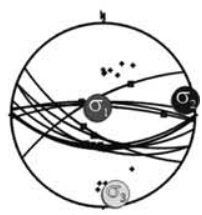

S103-BE

(a)

Fig. 4. Paleostress map and trajectory of $\sigma_{\mathrm{Hmax}}$ obtained for (a) Permian-Lower Triassic extensional tectonic event. Twenty field stations of measurements describe this event with $\sigma_{1}$ vertical. (b) Paleostress map and trajectory of $\sigma_{\text {Hmax }}$ obtained for Alpine-Eocene-present-day extensional and shear tectonic event. This event is described by 20 field stations of measurements with $\sigma_{1}(8)$ or $\sigma_{2}(12)$ vertical. In both figures, each station number is located into the granitic massif and the fracture activated by this stress field is plotted.

minimum horizontal stress value $\left(\sigma_{\mathrm{Hmin}}\right), \sigma_{\mathrm{y}}$ is the maximum horizontal stress value $\left(\sigma_{\mathrm{Hmax}}\right)$ and $\sigma_{\mathrm{z}}$ is the vertical stress value $\left(\sigma_{\mathrm{V}}\right)$.

In total, 1994 structural data were collected and 690 measurements of slickenside lineations on fault planes, at 123 locations. From stress inversion results, two main sets of stress tensors, defined by the orientation of the maximum horizontal stress $\left(\sigma_{\mathrm{Hmax}}\right)$, were determined (Fig. 4a and b) showing axial symmetry:

(1) Family A: $\sigma_{\mathrm{Hmax}}$ ranged between $\mathrm{N} 70^{\circ} \mathrm{E}$ and $\mathrm{N} 120^{\circ} \mathrm{E}$

\section{(2) Family B: $\sigma_{\mathrm{Hmax}}$ oriented $\mathrm{N} 150^{\circ} \mathrm{E}$ and $\mathrm{N} 010^{\circ} \mathrm{E}$}

The chronological relationship between the sets shows that the fault families of set A are older than faults of set B, established from field observations: overlapped slickenside on fault planes and fault traces crossed by others. The discrimination of fault families in both events was derived from three sources: (1) field observation of relative dating and data collected from absolute dating of episyenite quartz dykes (Galindo et al., 1994; González-Casado et al., 1996); (2) structures activated during each stress regime; and (3) 
compatible mechanical orientation of faults according to the principal axes of the paleostress regime described (De Vicente et al., 1996) and the character observed in field work: normal, reverse and strike-slip faults. Taking into account these data, as well as the regional geology (De Vicente et al., 2004) and chronological information (De Bruijne, 2001; Antón et al., 2004), two tectonic events have been interpreted as: (A) Upper Permian-Lower Triassic and (B) Alpine (Eocene-Present).

(A) Upper Permian-Lower Triassic tectonic event: extensional tectonics with a regional extension oriented $\mathrm{N} 10^{\circ} \mathrm{E}$ that activates normal faults oriented $\mathrm{E}-\mathrm{W}$, $\mathrm{N} 60^{\circ} \mathrm{E}$ dextral strike-slips and sinistral strike-slip fault oriented $\mathrm{N} 120^{\circ} \mathrm{E}$. Comparing these data with regional analyses (González-Casado et al., 1996), the age of this event is established between 290 and $300 \mathrm{Ma}$ (Upper Carboniferous-Lower Permian) and compatible with the movements described above.

(B) Alpine (Eocene-Present-day) tectonic event: faults recognized in the El Berrocal, with well-developed fault gauge, were dated in $79 \pm 3 \mathrm{Ma}$ by fission track and $\mathrm{K}-\mathrm{Ar}$ analysis techniques (Hidrobap Project, 1999). The strike-slip regime is defined by a NWSE-oriented stress tensor. This stress field activated reverse faults oriented NNE-SSW (e.g. South Border thrust fault; De Vicente et al., 1996), N-S strike-slip faults and it reactivates previous faults with a dextral NE-SW strike-slip movement.

\subsection{Dynamic structural map at scale 1:10 000}

The age correlation between the structures measured in fieldwork and the structures derived from remote-sensing is by orientation. As fractures interpreted at scale 1:10,000 in the El Berrocal massif were activated by the Permo-Triassic and Alpine tectonic events. The fracture sets that were mechanically compatible with these stress fields were filtered (Fig. 5). From this filtering, two maps of fractures at scale 1:10,000 were constructed: the Permian structural

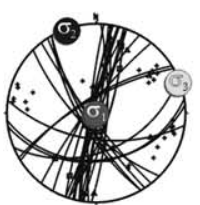

SR5

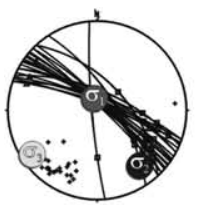

SR6B

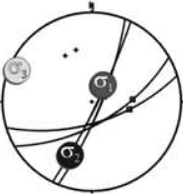

S7EDB

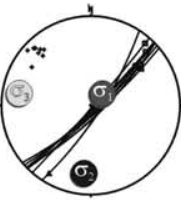

$\mathrm{S} 56 \mathrm{E}$

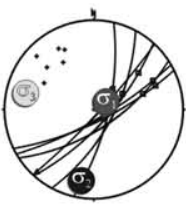

S62B

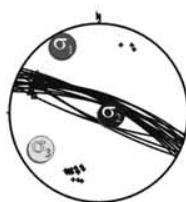

S69B

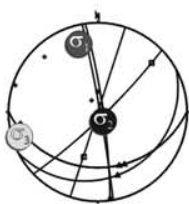

S73M

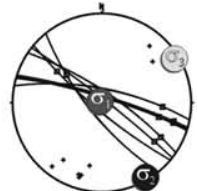

S16M

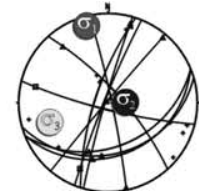

S20M

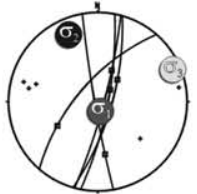

S26B

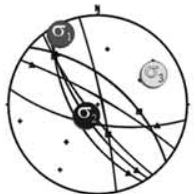

S49DC
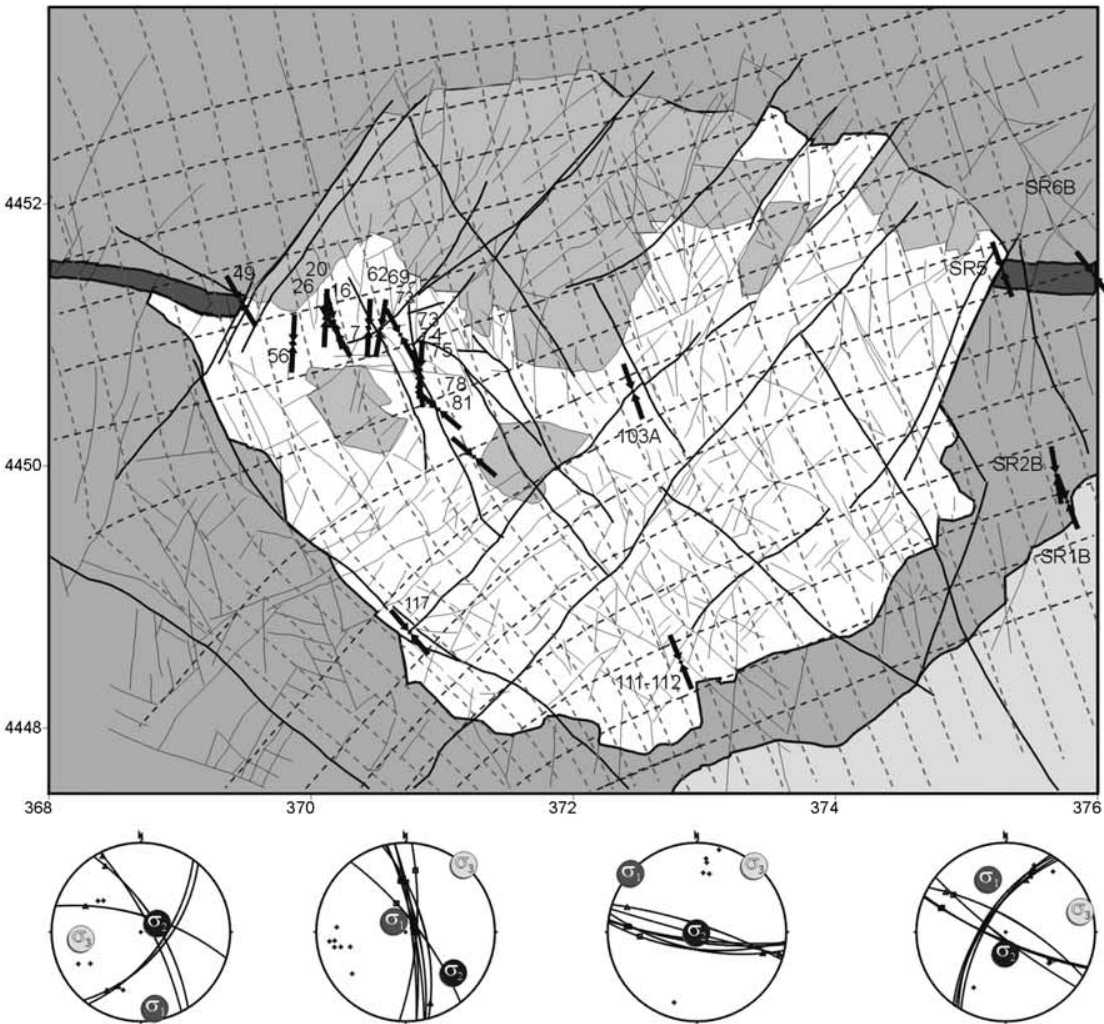

S75DB

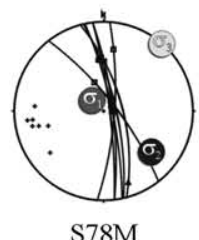

S78M

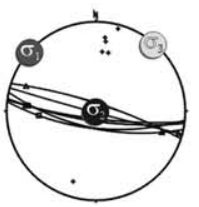

S81T

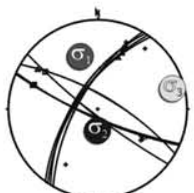

S103EB

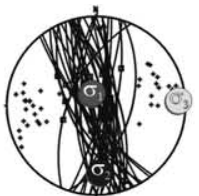

S74E

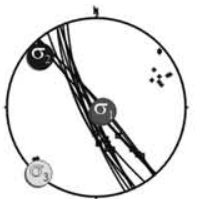

S117M

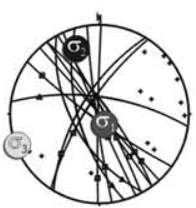

SR1B
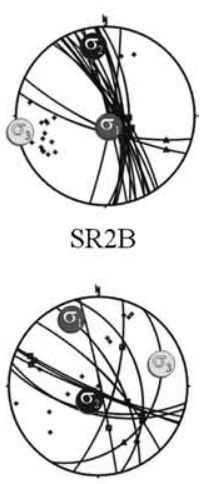

S111-12B

Fig. 4 (continued) 
fracture map (Fig. 5a), consisting of 498 fractures trending E-W, NNE-SSW, NE-SW and NW-SE, and the Alpine structural map (Fig. 5b), consisting of 340 fractures oriented $\mathrm{N}-\mathrm{S}$, NE-SW and NW-SE. Each map represents the fractures interpreted from DEMs, aerial photography and fieldwork that were active according to the paleostress fields defined by stress inversion results.

\section{Fractal analysis of dynamic fault patterns}

We have carried out a fractal analysis over the three structural maps obtained above (original fracture map, Permian and Alpine fracture maps), in order to determine the complexity of the spatial distribution of faults related to those tectonic fields. The fractal box-dimension was calculated for the structural map (original and filtered) at scale 1:10,000. Table 2 shows the dimension values obtained by box-counting. The fractal dimension is measured by the slope of the curve fitted from the bilogarithmic plot by maximum likelihood techniques (Fig. 6).

There are a few constraints necessary to carry out the fractal analysis over the structural maps and avoid spurious or biased numeric results. Firstly, the structural map must be containing fractures ranging over at least three orders of
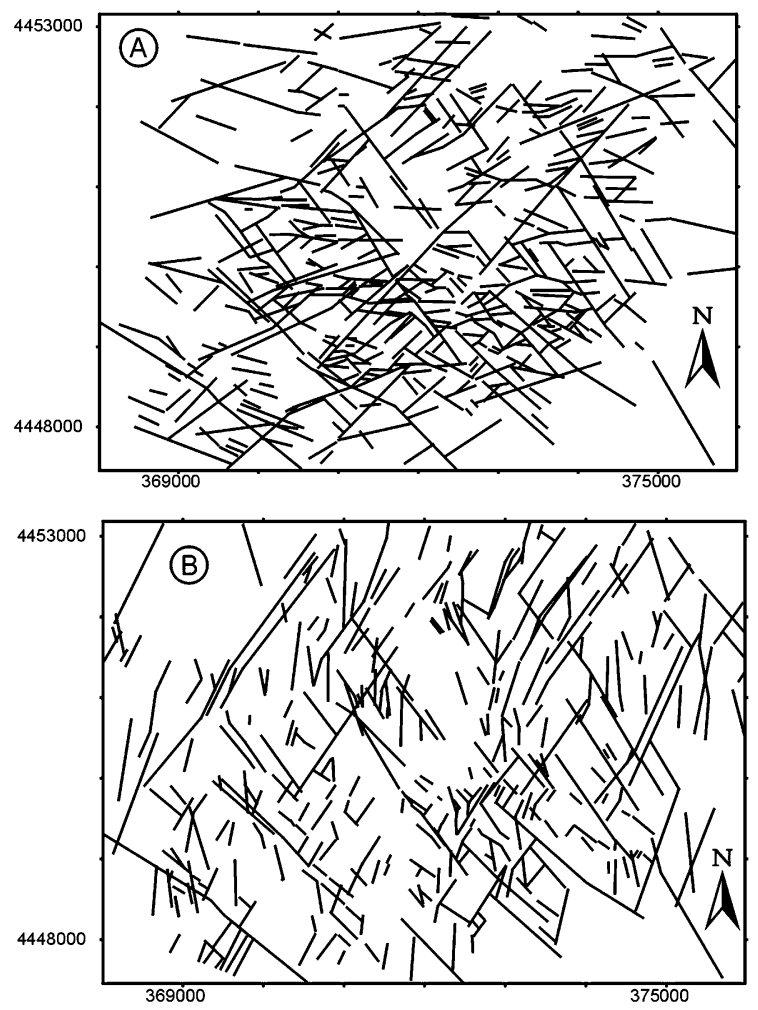

Fig. 5. Dynamic structural maps of lineaments at scale 1:10,000. (a) 498 lineaments activated by Permian-Lower Triassic tectonic event (mean orientations: E-W, NNE-SSW, NW-SE). (b) 340 lineaments activated by Alpine (Eocene-present-day) tectonic events main orientations: N-S, NESW, NW-SE). magnitude in size. In this analysis $(1: 10,000)$, the longest lineament is $6.1 \mathrm{~km}$ and the shortest is $82 \mathrm{~m}$. Therefore, the patterns of lineaments are representative of the strain accommodation from both tectonic events, as suggested by Scholz and Cowie (1990) and Marret and Allmendinger (1991). Also, the box sizes have to range between the inner cut-off and the outer cut-off. The lower limit is obtained from the length of the smallest fault, and the outer, upper value corresponds to the size of the maximum blank space on the structural map.

The values obtained here for the fractal dimension of the spatial fracture distribution indicate that the complexity of the original structural map $(D=1.86)$ is bigger than for the filtered maps, specifically $D=1.75$ for the Permian map and $D=1.79$ for the Alpine map. This means that the full map includes a greater level of spatial fault distribution than the filtered map. However, this property is obvious because the complete map includes fractures generated by two different tectonic events. Even so, the comparison between the fractal dimensions obtained for filtered maps is interesting because these maps represent the fracture pattern due to a particular stress field. Furthermore, this result agrees with the property of fractal sets whereby the fractal dimension of the set included within another set is either less or equal to the embedding set (Hasting and Sugihara, 1993), showing that the analysis is robust.

The fractal dimension of filtered maps indicates the degree of complexity due to the geometric irregularity of spatial fracture patterns caused by the different stress fields. As the fractal dimension is bigger in the Alpine fracture map $(D=1.79)$ than in the Permian fracture map $(D=1.75)$, the Alpine fracture pattern is more complex than the Permian fracture pattern. Because the Alpine fracture pattern is formed by newly formed and several reactivated families of fractures (NW-SE; see the lower corners of Fig. 5a and b), the spatial complexity is greater than in the Permian stress field. This observation is in accordance with the fractal analysis carried out above.

The next step in order to analyse the relationship between the fractal dimension and the stress tensor regime consists of studying the spatial fractal anisotropy.

\section{Analysis of the fractal anisotropy}

The fractal dimension obtained above shows the maximum fractality of the 2-D fracture maps. However,

Table 2

Fractal box-dimension obtained by box-counting on the total structural map and dynamic filtered fracture map at scale 1:10,000

\begin{tabular}{ll}
\hline Fracture map & Fractal dimension $D$ \\
\hline Original map of fractures & 1.86 \\
Alpine (Eocene-present-day) fracture map & 1.79 \\
Permian-Lower Triassic fracture map & 1.75 \\
\hline
\end{tabular}




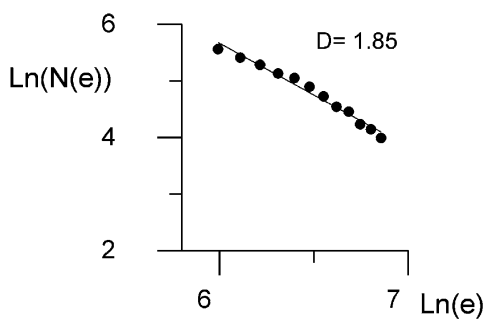

Fig. 6. Bilogarithmic curve obtained by box counting covering the structural map of lineaments (Fig. 2-centre) at scale 1:10,000. The fit was achieved using the maximum likelihood technique and the slope corresponds to the fractal box-dimension, $D=1.86$.

the grid covers the entire fracture map and, therefore, it does not indicate the direction of maximum complexity or fractality if they exist. This direction exists because the fracture density is heterogeneous along the map; the number of faults in each box is not constant. From this idea, it is possible to affirm that the fractal dimension of the spatial distribution of fault is anisotropic. The question is how to measure this anisotropy.

Pérez-López et al. (2000) propose a methodology to obtain the bidimensional fractal anisotropy. These authors obtain the fractal box-dimension over transects across the structure map (normal to the mean fracture sets directions) and show fracture profiles with a structure similar to a Cantor's Dust (Fig. 7). This methodology is based on Cantor's Dust analysis of faults applied by Velde et al. (1990) and revised by Harris et al. (1991). Recently, Volland and Kruhl (2004) have proposed a similar methodology to obtain patterns of anisotropies in a Hercynian fault zone. These authors determine the azi- muthal anisotropy of the fractal dimension by applying the Cantor's Dust method in the analysis of 1-D frequency-size distribution of fragments. They conclude that two patterns of fault genesis were recognized.

The fractal dimensions obtained by Pérez-López et al. (2000) range between 0.58 and 0.51. However, when applying the same transects over the dynamic filtered maps, these authors found that the fractal dimension ranged between 0.53 and 0.79 . This last result shows a greater difference between the maximum and minimum values of fractal dimension of the filtered map than the fractal dimension obtained from the complete fracture map.

\subsection{Methodology to measure the anisotropy}

In order to realize a systematic coverage of transects for the structural fracture maps obtained above, a computer code, called AFA, was designed Firstly, AFA obtains the fracture profile on transects taken at $10^{\circ}$ increments, oriented from the north to the south and covering $180^{\circ}$ (Fig. 8-left). However, the intersections between faults and the profiles obtained depend on the location of the rotation centre. Perez Lopez (2003) suggests that there is a minimum value of fault intersection on a fracture profile, the mass number. To prevent the effect of the lack of mass, the AFA code draws several transects with the same orientation and separated by a $\delta$-factor (Fig. 8-right). These similar profiles are added in one unique profile and the maximum irregularity is incorporated into the analysis. Over this unique profile we have achieved the 1-D box counting for

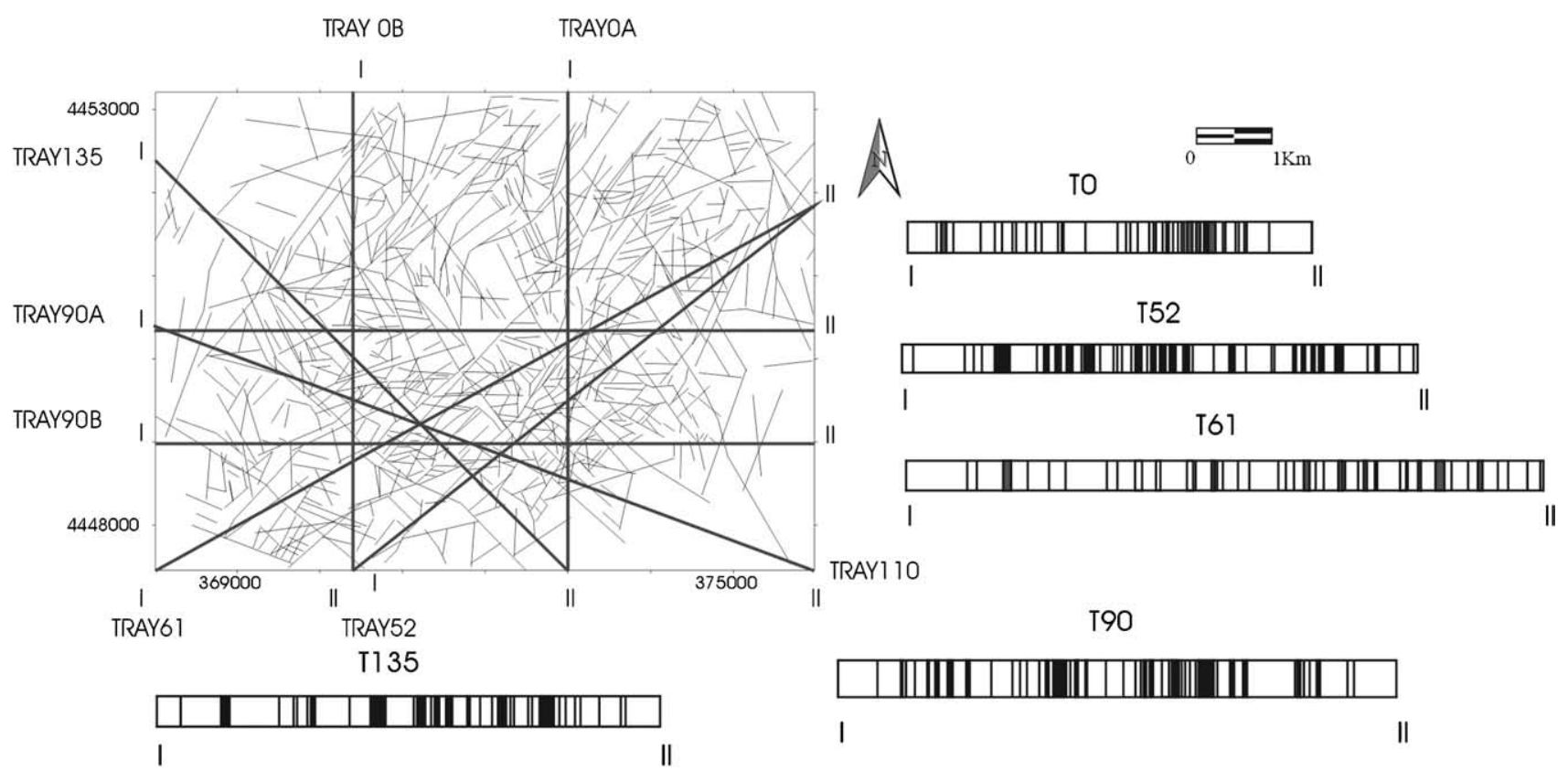

Fig. 7. One-dimensional transects cutting the structural fracture map at scale 1:10,000. The strike of these transects is obtained from the main fracture directions from the rose diagram. The fracture profiles are obtained by recording the intersections between each transect and fracture. Over these fracture profiles, the fractal dimension is calculated by a 1-D box-counting. After Pérez-López et al. (2000). 
the original fracture maps and filtered maps (Permian and Alpine structural maps).

Fig. 9 shows the ellipses obtained from polar plot of the fractal dimension vs. the orientation of the profile. The polar plot draws an orientated vector where the module of the vector is the fractal dimension and the angle is the transect orientation. The north position is located at the upper $y$-axis. These ellipses show the fractal anisotropy of the spatial distribution of fractures into the three fracture maps at 1:10,000 scale.

The Permo-Triassic ellipse shows the maximum horizontal fractal dimension $\left(D_{\mathrm{Hmax}}=0.70\right)$ oriented $\mathrm{N} 168^{\circ} \mathrm{E}$ (NNW-SSE). The Alpine ellipse shows $D_{\text {Hmax }}=0.75$, oriented ESE-WNW. The complete fracture map has a $D_{\text {Hmax }}=0.80$, oriented NW-SE. These ellipses were fitted by a minimum square method (Hart and Rudman, 1997) to get the best ellipse parameters and the anisotropy eccentricity coefficient.

Table 3 summarises the parameters for the total fracture map and for the filtered maps, Permian and Alpine maps of fractures: $D_{\text {Hmax }}$ value, $D_{\text {Hmin }}$, mean, ellipse fit equation, variance, anisotropy coefficient and $D_{\text {Hmax }}$ orientation. The total fracture map shows the maximum value of fractal dimension.

Plotting polar graphs of the ellipses obtained and the orientation of $\sigma_{\mathrm{Hmax}}$ for Permian (Fig. 10-left) and Alpine stress fields (Fig. 10-right) shows a relationship between $\sigma_{\text {Hmax }}$ and $D_{\text {Hmax }}$. From this analysis, $\sigma_{\text {Hmax }}$ is normal to $D_{\text {Hmax }}$. This geometrical relationship can be interpreted to show that the maximum fracture pattern complexity is perpendicular to $\sigma_{\text {Hmax }}$, from a 2-D analysis. However, this analysis does not determine the relevance of the stress field regime for this geometric relationship because this analysis is performed in two dimensions. In order to determine the relationship between the fractal anisotropy and the tectonic regime, we have to work in three dimensions, defining the stress ellipsoid $\left(\sigma_{1}, \sigma_{2}\right.$ and $\left.\sigma_{3}\right)$ and the fractal ellipsoid, described in the next section.

\section{Fractal ellipsoid from 3-D spatial fractures distribution}

One way to calculate the tectonic stress field is based on taking measures of the orientation of the principal stress axis, $\sigma_{1}, \sigma_{2}$ and $\sigma_{3}$ and the shape of the stress ellipsoid $\left(R^{\prime}\right)$ (Reches, 1987). From the definition of the parameter $R^{\prime}$ (Eq. (1)), we have defined the $F$-parameter as:

$$
F=\frac{D_{\mathrm{Z}}-D_{\mathrm{Hmin}}}{D_{\mathrm{H} \max }-D_{\mathrm{Hmin}}}
$$

where $D_{\mathrm{Z}}$ is the fractal dimension of spatial fracture

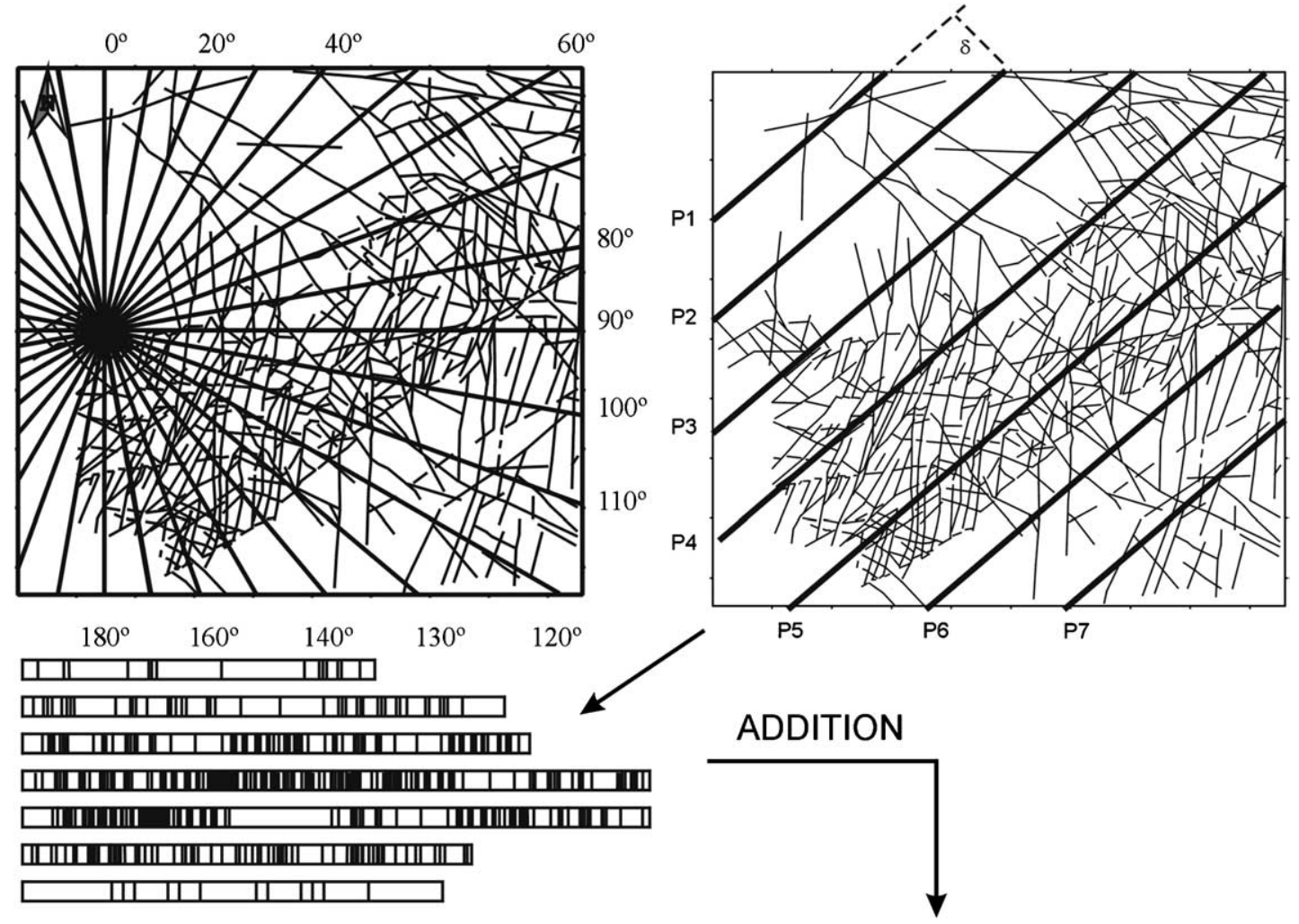

$\mathrm{P} 1+\mathrm{P} 2+\mathrm{P} 3+\mathrm{P} 4+\mathrm{P} 5+\mathrm{P} 6+\mathrm{P} 7=\mathrm{P}\left(45^{\circ}\right)$ 

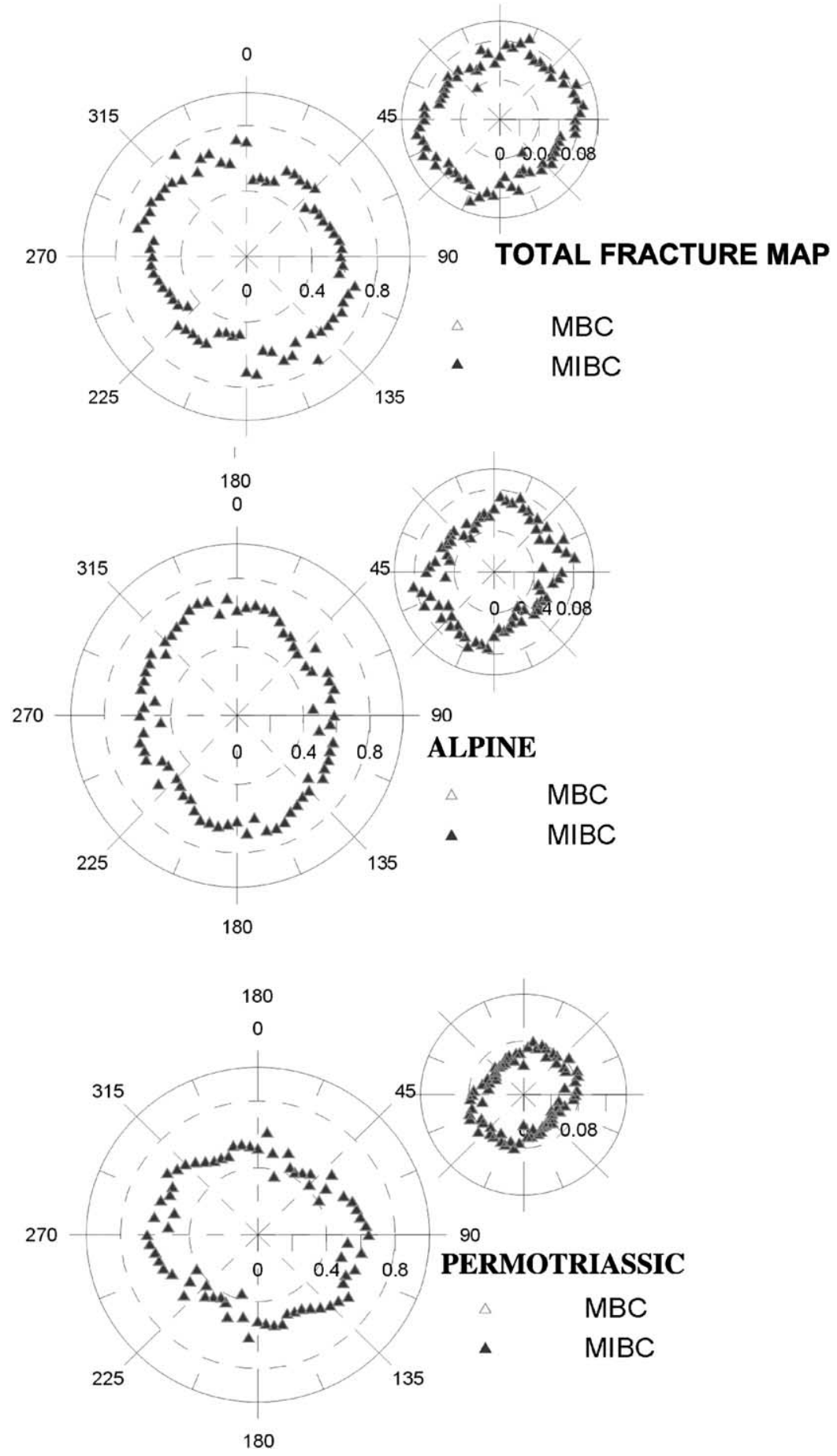

Fig. 9. Polar plots of the 1-D fractal dimension, calculated by AFA code over fracture profiles for fracture maps at scale 1:10,000. The technique used for taking measures of the fractal dimension was 1-D box-counting. Lower ellipses correspond to Permo-Triassic and Alpine results for filtered maps. Positive $y$-axis is oriented towards north $\left(0^{\circ}\right)$ and the values of the small upper right ellipses show the residual value obtained by the code AFA.

distribution for vertical sampling, $D_{\mathrm{Hmax}}$ is the maximum horizontal fractal dimension and $D_{\mathrm{Hmin}}$ is the minimum horizontal fractal dimension.

Therefore, according to the stress tensor regime defined by the stress ratio $R^{\prime}$ (Anderson, 1951) and the relationship between $\sigma_{\mathrm{Hmax}}$ (equivalent to $\sigma_{\mathrm{y}}$ ) and $D_{\mathrm{Hmax}}$ (equivalent to $D_{\mathrm{x}}$ ), mutually perpendicular, is possible to establish the stress field analogy between both parameters as is shown in Table 4.

We have used a vertical 600-m-deep borehole drilled by the Hidrobap Project (1999) in order to obtain the $D_{\mathrm{z}}$ fractal dimension. The fracture orientations were interpreted from a BHTV log of the borehole. The fractures measured are oriented NE-SW principally and were filtered according to 
Table 3

Parameters of the ellipse adjustments from the polar plot (Fig. 9). $D_{\mathrm{Hmax}}$ is the maximum horizontal fractal dimension; $D_{\mathrm{Hmin}}$ is the minimum horizontal fractal dimension. The fittest ellipse formula is obtained by the code proposed by Hart and Rudman (1997). C.A. represents the coefficient of anisotropy and $\theta$ is the orientation of $D_{\mathrm{Hmax}}$

\begin{tabular}{lllllll}
\hline Map & $D_{\text {Hmax }}$ & $D_{\text {Hmin }}$ & Mean & Ellipse & Variance & C.A. \\
\hline Total & 0.76 & 0.47 & 0.59 & $x^{2}+0.45 x y+0.9 y^{2}$ & 0.005 & 1.27 \\
Alpine & 0.65 & 0.36 & 0.54 & $0.8 x^{2}+0.3 x y+1.1 y^{2}$ & 0.005 & 1.23 \\
Permian & 0.69 & 0.50 & 0.62 & $1.5 x^{2}+0.3 x y+0.9 y^{2}$ & 0.002 & $\mathrm{~N} 110^{\circ} \mathrm{E}$ \\
\hline
\end{tabular}

the same criteria applied to structural data obtained from surface analysis. The fractal dimension was calculated for the total set and for fracture maps filtered for the PermoTriassic and Alpine tectonic stress fields. The fractal dimension calculated is summarised in Table 5. The vertical fractal dimension for original structural map $\left(D_{\mathrm{z}}=0.84\right)$ is bigger than Alpine $\left(D_{\mathrm{z}}=0.80\right)$ and Permian $\left(D_{\mathrm{z}}=0.79\right)$.

According to the analogy shown in Table 4 and the $F$ values for Alpine and Permo-Triassic fracture patterns (bigger than one with $D_{\mathrm{z}}>D_{\mathrm{Hmax}}$ ), both regimes are defined as triaxial extension.

\section{Discussion}

\subsection{Dynamic filtering of structural map}

The tectonic regime deduced from stress inversion analysis represents a powerful tool in order to filter fracture maps interpreted from digital elevation models (DEM), ortho-photography and field-mapping. By using the stress ellipse parameters, orientation of main horizontal stress $\left(\sigma_{\mathrm{Hmax}}, \sigma_{\mathrm{H} \min }\right)$ and stress ratio $\left(R^{\prime}\right)$, it is possible to discriminate between fractures sets that are mechanically compatible with the different stress fields. This analysis is performed at several scales in order to establish the selfsimilarity behaviour of the structures interpreted.

In this work, we have presented fracture maps at 1:2000, 1:10,000, 1:500,000 scales, and these maps, show fracture
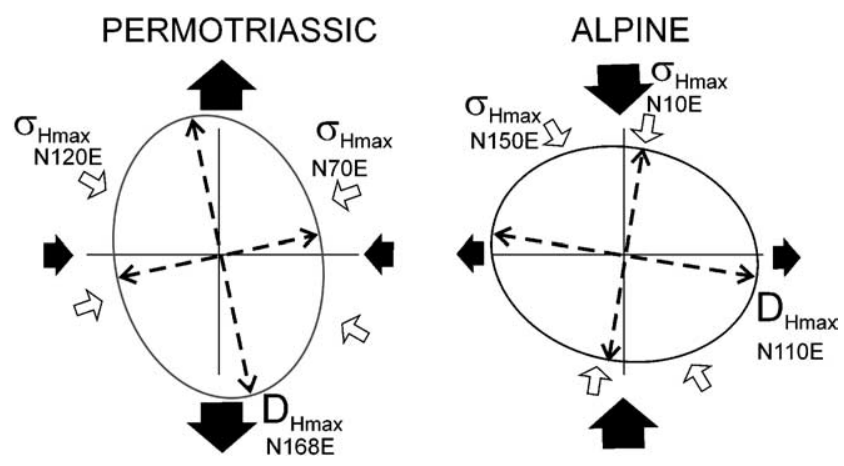

Fig. 10. Fitted ellipses of fractal anisotropy and stress tensor orientation. Left: Permo-Triassic stress field, triaxial extension with $\sigma_{\text {Hmax }}$ oriented E$\mathrm{W}$ and $D_{\mathrm{Hmax}}$ close to $\mathrm{N}-\mathrm{S}$. Right: Alpine stress field, triaxial extension with $\sigma_{\mathrm{Hmax}}$ oriented $\mathrm{N}-\mathrm{S}$ and $D_{\mathrm{H} \max }$ close to E-W. Black arrows represent the values of $\sigma_{\mathrm{Hmax}}$ and $\sigma_{\mathrm{Hmin}}$ while white arrows correspond to local stress tensors calculated by stress inversion. sets generated by the tectonic events described in precedent sections (Permo-Triassic and Alpine). From these maps, which is the better choice to carry out the fractal anisotropy analysis? There is an optimal scale of fracture map, giving a better representation of fracture patterns due to particular stress fields, and this optimal scale best shows the fractal anisotropy of spatial faults distribution. Among all the maps presented here, the optimal scale estimated in this work is $1: 10,000$ because it shows the best and most complete spatial fracture distribution (2-D) from the two tectonic events, Upper Permian-Lower Triassic and Alpine, respectively. The fracture map with scale 1:2000 represents a local tectonic behaviour controlled by Variscan dikes and normal faults oriented from east to west, for instance, whereas the map 1:500,000 includes several regional and local stress fields generated during other tectonic events. Therefore, the optimal scale to estimate the best 2-D representation of fracture patterns of a particular stress field is not a fixed value, because this parameter depends on many geological factors (e.g. lithology), tectonic (intraplate stresses, active borders, extensional tectonics, oceanic ridge, strike-slip tensors, etc.), strain accommodation (dykes, veins, faults, folds, etc.) and the geometric criteria of structural representation (joints, diaclases lines, mechanical contact, shear bands...).

\subsection{The fractal analysis of fracture maps}

Two-dimensional fractal analysis of fracture maps provides a quantification of the complexity of the geometric fracture patterns. The fractal analysis that was carried out on the fracture maps, and which was generated by several tectonic stages, only indicates the quantification of the geometric complexity but without any relationship with any geological and tectonic interpretation. Accordingly, in this work we have filtered the fracture maps, taking into account the stress inversion results, to obtain a fractal dimension associated with each fracture pattern. Since the fracture pattern is a consequence of the tectonic stress field, the fractal dimension calculated shows the geometric complexity of the Permo-Triassic (PT) and the Alpine (AP) tectonic stages, both affecting the El Berrocal granite massif. In this case, the PT stress field activates fractures mainly oriented E-W, NNE-SSW, NW-SE, while the AP event activates fractures oriented $\mathrm{N}-\mathrm{S}, \mathrm{NE}-\mathrm{SW}$ and reactivates previous NW-SE PT fractures. 
Table 4

Analogy between the $R^{\prime}$ parameter, the $F$ factor and the tectonic stress field according to the empirical relationship between $D_{\mathrm{Hmax}}\left(D_{\mathrm{x}}\right), D_{\mathrm{Hmin}}\left(D_{\mathrm{y}}\right), D_{\mathrm{z}}$ and $\sigma_{\mathrm{Hmax}}\left(\sigma_{\mathrm{y}}\right), \sigma_{\mathrm{Hmin}}\left(\sigma_{\mathrm{x}}\right)$ and $\sigma_{\mathrm{z}}$

\begin{tabular}{|c|c|c|c|c|}
\hline$R^{\prime}$ & Axis & $\mathrm{F}$ & Axis & Stress field \\
\hline$R^{\prime} \Rightarrow-\infty$ & $\sigma_{\mathrm{y}}=\sigma_{\mathrm{x}}>\sigma_{\mathrm{z}}$ & $F \Rightarrow-\infty$ & $D_{\mathrm{z}}>D_{\mathrm{x}}=D_{\mathrm{y}}$ & Radial compression \\
\hline$R^{\prime}<0$ & $\sigma_{\mathrm{y}}>\sigma_{\mathrm{x}}>\sigma_{\mathrm{z}}$ & $F<0$ & $D_{\mathrm{x}}>D_{\mathrm{y}}>D_{\mathrm{z}}$ & Triaxial compression \\
\hline$R^{\prime}=0$ & $\sigma_{\mathrm{y}}>\sigma_{\mathrm{x}}=\sigma_{\mathrm{z}}$ & $F=0$ & $D_{\mathrm{x}}=D_{\mathrm{z}}>D_{\mathrm{y}}$ & Uniaxial compression \\
\hline $0<R^{\prime}<1$ & $\sigma_{\mathrm{y}}>\sigma_{\mathrm{z}}>\sigma_{\mathrm{x}}$ & $0<F<1$ & $D_{\mathrm{x}}>D_{\mathrm{z}}>D_{\mathrm{y}}$ & Shear field \\
\hline$R^{\prime}=1$ & $\sigma_{\mathrm{z}}=\sigma_{\mathrm{y}}>\sigma_{\mathrm{x}}$ & $F=1$ & $D_{\mathrm{x}}>D_{\mathrm{y}}=D_{\mathrm{z}}$ & Uniaxial extension \\
\hline$R^{\prime}>1$ & $\sigma_{\mathrm{z}}>\sigma_{\mathrm{y}}>\sigma_{\mathrm{x}}$ & $F>1$ & $D_{\mathrm{z}}>D_{\mathrm{x}}>D_{\mathrm{y}}$ & Triaxial extension \\
\hline$R^{\prime} \Rightarrow+\infty$ & $\sigma_{\mathrm{z}}>\sigma_{\mathrm{y}}=\sigma_{\mathrm{x}}$ & $F \Rightarrow+\infty$ & $D_{\mathrm{y}}=D_{\mathrm{x}}>D_{\mathrm{z}}$ & Radial extension \\
\hline
\end{tabular}

From a fractal point of view, the calculated fractal dimension of the PT structure pattern is lower $(D=1.75)$ than the fractal dimension of the AP pattern $(D=1.79)$. These values agree with the idea that the more recent tectonic stage (Alpine) reactivates previous fractures and, consequently, the fracture pattern shows a higher complex geometry. However, the difference between the two values is not very significant if used to establish a structural fractal criterion for fracture patterns, as the box-counting analysis is very sensitive to the initial condition of analysis, i.e. phenomena associated with the truncation of fault traces represented by the 2-D map (Harris et al., 1991; Gillespie et al., 1993; Dorcel, 2002).

\subsection{Fractal anisotropy and tectonic stress tensor}

Volland and Kruhl (2004) apply the compass-counting technique (Velde et al., 1990) in order to determine the fractal anisotropy on a Permian granitic massif in a similar way to our application of the same technique in order to determine the relevance of the stress tensor in relation to the principal fracture patterns recognized. Both techniques generate a fractal anisotropy value but the interpretation and the mechanism applied are different in each case. Volland and Kruhl (2004) have carried out a systematic analysis of frequency-size distribution of quartz at micro scale and in differing orientations of $10^{\circ}$ increments from a starting point. The material analysed was the fault gauge of a filled fracture. However, in this work we have analysed spatial fracture distribution at several meso- and macroscales and we have carried out a systematic analysis of spacing by orientation. In both cases, the result obtained arises from geometrical sets with a Cantor's Dust structure and the compass-counting technique was used. Because the fragmentation processes and the fracturing processes are a consequence of the stress fields, in both analyses we can interpret the relationship of the anisotropy to fracture patterns.

On the basis of the compass-counting technique, which was applied to the fracture profiles at 1:10,000 scale, we have determined the fractal dimension of these profiles. We have obtained parallel transects separated by $\delta$-factor and rotated $10^{\circ}$ from north to south in a similar way to the rotation suggested by Volland and Kruhl (2004). However, we have applied this analysis on fracture maps filtered by dynamic criteria, showing that the fractal anisotropy is representative of a particular tectonic stress stage.

The main objective of this analysis is to determine the reliability of the Cantor's Dust set as a representative value of the space between fractures and the relationship between the fractal dimension and the structural properties of the fracture patterns. We have represented the anisotropy by using a polar plot of the oriented 1-D fractal dimension. Since the curve obtained is symmetric with respect to the origin, we distributed the values measured between 0 and $360^{\circ}$. The points of the curve are placed around the origin (centre of symmetry) and the aspect of the curve is close to an ellipse. Furthermore, the plot of the ellipse of the fractal dimension along with the orientation of $\sigma_{\mathrm{Hmax}}$ on the same plot shows that the orientation of $\sigma_{\mathrm{H} \max }$ lies at $90^{\circ}$ to the orientation of $D_{\mathrm{Hmax}}$. This suggests that the maximum fracture geometry complexity is normal to the $\sigma_{\mathrm{Hmax}}$ orientation.

The relationship between $D_{\mathrm{H} \max }$ and $\sigma_{\mathrm{H} \max }$ is robust for Permo-Triassic and Alpine fractal analyses (Fig. 10). This means that this relationship between these parameters is a geometric characteristic of the fracture pattern due to a particular stress field. Therefore, there is a direct relationship between the fractal ellipsoid and the principal axes of the stress tensor. Accordingly, we have defined the $F$ parameter (Eq. (2)) in order to characterize the stress regime by the azimuthal anisotropy of the fractal dimension. According to the values shown in Tables 4 and 5, the stress

Table 5

Values of the axes of the fractal ellipsoid for Permo-Triassic and Alpine fracture patterns and tectonic regime obtained from Table 4

\begin{tabular}{lllllll}
\hline Tectonic event & $D_{\mathrm{z}}$ & $D_{\mathrm{Hmax}}$ & $D_{\text {Hmin }}$ & $\mathrm{F}$ & Relation & Tectonic regime \\
\hline Alpine & 0.80 & 0.65 & 0.36 & 1.52 & $D_{\mathrm{z}}>D_{\mathrm{x}}>D_{\mathrm{y}}$ & Triaxial extension \\
Permo-Triassic & 0.79 & 0.69 & 0.50 & 1.53 & $D_{\mathrm{z}}>D_{\mathrm{x}}>D_{\mathrm{y}}$ & Triaxial extension \\
\hline
\end{tabular}


field affecting the El Berrocal granite massif is defined as triaxial extension. Dominant faults measured in field are normal and normal/strike-slip. The main differences between Alpine and Permo-Triassic stress fields are the orientation of $\sigma_{\mathrm{Hmax}}$ and the parameter that characterizes the tectonic behaviour: extensional strike-slip in both cases. The values found in Table 5 show that the shape factor of the anisotropy fractal ellipse does not show a significant variation as the stress inversion results suggest and the Permo-Triassic and Alpine tensors are extensional strikeslip.

Finally, we have defined the ellipsoid of the azimuthal anisotropy of the fractal dimension, flattened and constrictional, and their correlation with the stress ellipsoid defined by $\sigma_{\mathrm{x}}, \sigma_{\mathrm{y}}$ and $\sigma_{\mathrm{z}}$ (Fig. 11). The flattened ellipsoid of the fractal anisotropy is linked with the constrictional stress ellipsoid and vice versa (Fig. 11) since it is a consequence of the perpendicular relationship between $D_{\mathrm{H} \max }$ and $\sigma_{\mathrm{Hmax}}$.

\section{Conclusions}

The fractal dimension, measured from fracture maps filtered by stress inversion results, shows the geometric complexity of the fracture pattern formed by fractures mechanically compatible with the paleostress field recognized.

By using 1-D fracture profiles, it is possible to determine the fractal anisotropy of the spatial fracture distribution, active during a particular paleostress field. This anisotropy is an ellipse where the long axis is the maximum horizontal fractal dimension, $D_{\mathrm{Hmax}}$, and the short axis is the minimum horizontal fractal dimension, $D_{\mathrm{Hmin}}$.

The obtained results suggest a geometric relationship between the stress tensor and the fractal anisotropy ellipse, i.e. that the orientation of $\sigma_{\mathrm{Hmax}}$ is normal to the orientation of $D_{\text {Hmax }}$.

From the analogy of the orientations between $\sigma_{\mathrm{Hmax}}=\sigma_{\mathrm{y}}$, $\sigma_{\mathrm{H} \min }=\sigma_{\mathrm{x}}$ and $\sigma_{\mathrm{z}}$ with $D_{\mathrm{H} \max }=D_{\mathrm{x}}, D_{\mathrm{H} \min }=D_{\mathrm{y}}$ and $D_{\mathrm{z}}$, it is possible to define the fractal anisotropy ellipsoid by a factor so-called ' $F$ '. This $F$ parameter, and subsequently the fractal anisotropy of fault distribution, defines the tectonic stress fields in a similar way to the stress ratio $R$.

\section{Acknowledgements}

Thanks are given to the reviewers Dr Tim Needham and Dr Stefano Mazzoli for their comments and clear reviews in order to improve the manuscript and the English style. We thank the Consejo de Seguridad Nuclear of Spain and ENRESA for supporting partially this work. We also thank Dr Julio Pardillo for the borehole dataset and Dr Armando Cisternas, from EOST-Institut de Globe du Strasbourg, for his kind remarks about the manuscript. This work was developed in the frame of the HIDROBAP project: hydrogeology of low permeability media and represents a part of the thesis defended by the principal author. The English style was revised by Dr Castiñeira from Colorado University at Boulder and USGS of Denver and Dr Liz

\section{TECTONIC STRESS REGIME}

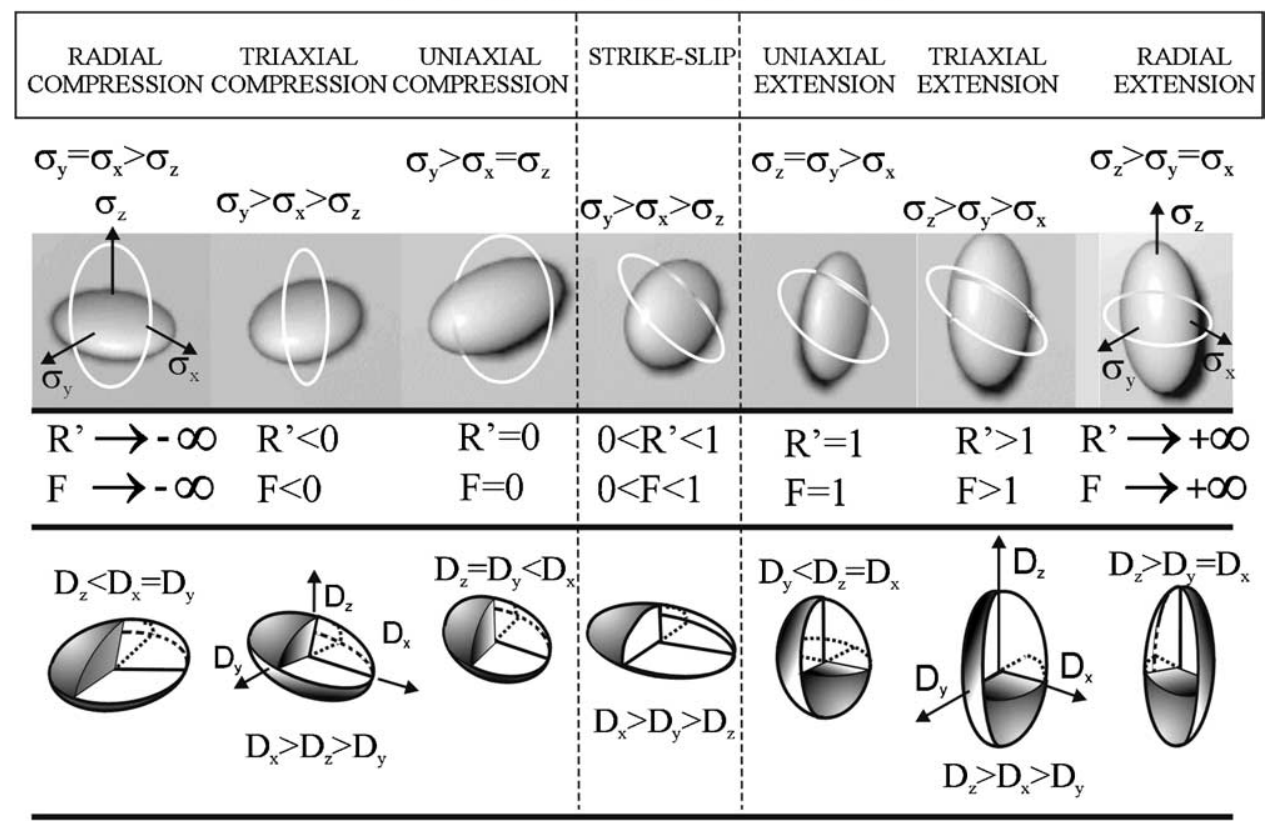

Fig. 11. Relationship between the stress tensor and the ellipsoid of the fractal anisotropy. From the stress ratio, $R^{\prime}$ and the $F$ parameter, it is possible to establish a relationship between the ellipsoid of the fractal anisotropy and the tectonic stress regime. In the case of the El Berrocal massif, stress inversion as fractal analysis shows a triaxial extension with $R^{\prime}$ and $F>1$. 
Thompson from Midland Valley Exploration (Scotland)— thanks for your kind help and good directions.

\section{References}

Anderson, E.M., 1951. The Dynamics of Faulting. Oliver and Boyd, Edinburgh. 133pp.

Angelier, J., 1979. Determination of the mean principal direction of stresses for a given fault population. Tectonophysics 56, 17-26.

Antón, L., Muñoz, A., De Vicente, G., 2004. Análisis de la fracturación y campos de paleoesfuerzos en el centro-oeste de la Península Ibérica. Geotemas 6 (3), 17-20 (in Spanish).

Barton, C., La Pointe, P.R., 1995. Fractal analysis of scaling and spatial clustering of fractures. In: Barton, C., La Pointe, P.R. (Eds.), Fractal in Earth Science. Plenum Press, New York, pp. 141-178.

Bott, M.P.H., 1959. The mechanism of oblique slip faulting. Geological Magazine 96, 109-117.

Campos, R., Martín-Benavente, C., Pérez del Villar, L., Pardillo, J., Fernández-Díaz, M., Quejido, A., De la Cruz, B., Rivas, P., 1996. El Berrocal. Aspectos geológicos: litología y estructura a escala local y de emplazamiento. Geogaceta 20 (7), 1618-1621 (in Spanish).

Capote, R., De Vicente, G., González-Casado, J.M., 1990. Evolución de las deformaciones alpinas en el Sistema Central Español. Geogaceta 7, 20 22 (in Spanish).

Casquet, C., Fuster, J.M., González-Casado, J.M., Peinado, M., Villaseca, C., 1988. Extensional tectonics and granite emplacement in the Spanish Central System, a discussion, in: Banda, E., Mendes, V. (Eds.), Fifth EGT Workshops: The Iberian Peninsula, pp. 65-77.

Castaing, C., Halawani, M.A., Gervais, F., Chilés, J.P., Genter, A., Bourgine, B., Ouillon, G., Brosse, J.M., Martin, P., Genna, A., Janjou, D., 1996. Scaling relationship in intraplate fracture systems related to Red Sea rifting. Tectonophysics 262, 291-314.

De Bruijne, C.H., 2001. Denudation, intraplate tectonics and far field effects; an integrated apatite fission track study in central Spain. Ph.D., Vrije Universiteit, Amsterdam, 164pp.

De Vicente, G., Giner, J.L., Muñoz-Martín, A., González-Casado, J.M., Lindo, R., 1996. Determination of present-day stress tensor and neotectonic interval in the Spanish Central System and Madrid basin, Central Spain. Tectonophysics 266, 405-424.

De Vicente, G., Vegas, R., Guimerá, J., Cloetingh, S., 2004. Estructura Alpina del Antepaís Ibérico, in: Vera, J.A. (Ed.), Geología de España Capítulo, 7. SGE-IGME, Madrid, pp. 619-625 (in Spanish).

Dorcel, C., 2002. Correlations dans les réseaux de fractures: caractérisation et conséquences avec les propiétés hydrauliques. Doctoral Thesé, University of Rennes (in French).

Etchecopar, A., Vasseur, G., Daigneres, M., 1981. An inverse problem in micro tectonics for the determination of stress tensor from fault striation analysis. Journal of Structural Geology 3, 51-65.

Galindo, C., Tornos, F., Darbyshire, D.P.F., Casquet, C., 1994. Rb and K/Ar chronology of dikes from the Sierra de Guadarrama, Spanish Central System. Geogaceta 16, 23-26.

Gillespie, P.A., Howard, C.B., Walsh, J.J., Watterson, J., 1993. Measurement and characterisation of spatial distribution of fractures. Tectonophysics 226, 113-141.

González-Casado, J.M., Caballero, J.M., Casquet, C., Galindo, C., Tornos, F., 1996. Palaeostress and geotectonic interpretation of the Alpine Cycle onset in the Sierra del Guadarrama (eastern Iberian Central System), based on evidence from episyenites. Tectonophysics 262, 213-231.
Harris, C., Franssen, R., Loosveld, R., 1991. Fractal analysis of fractures in rocks: the Cantor's Dust method comment. Tectonophysics 198, 107115.

Hart, D., Rudman, A.J., 1997. Least-square fit of an ellipse to anisotropic polar data: application to azimuthally resistivity surveys in karst regions. Computers \& Geoscience 23, 189-194.

Hasting, H.M., Sugihara, H., 1993. Fractals: a User's Guide for the Natural Sciences. Oxford Science Publications, Oxford. 235pp.

Hidrobap Project, 1999. Final Open Report, Project no. 0703305. Capítulo 2: Análisis tectónico y petrológico. ENRESA-CSN (Eds.). Consejo de Seguridad Nuclear, Madrid, 85pp (in Spanish).

Lee, J.C., Angelier, J., 1994. Paleostress trajectories maps based on the results of local determinations: the lissage program. Computers and Geosciences 20, 161-191.

Mark, D.M., Goodchild, M.F., 1986. On the ordering of two-dimensional space: introduction and relation to tesseral principles, in: Díaz, B.M., Bell, S.B.M. (Eds.), Spatial Data Processing using Tesseral Methods. NERC, Unit for Thematic Information Systems, Natural Environment Research Council, Swindon, Great Britain, pp. 179-192.

Marret, R., Allmendinger, R.W., 1991. Estimates of strain due to brittle faulting: sampling of fault populations. Journal of Structural Geology $13,47-50$.

Muñoz-Martín, A., Cloetingh, S., De Vicente, G., Andeweg, B., 1998. Finite element modelling of Tertiary paleostress fields in the eastern border of the Tajo basin (central Spain). Tectonophysics 300, 47-62.

Paredes, C., Elorza, F.J., 1999. Fractal and multifractal analysis of fractured geological media: surface-subsurface correlation. Computers \& Geoscience 25, 1081-1096.

Perez Lopez, R., 2003. On chaos theory applied in seismotectonics: fractal geometry of faults and earthquakes. European Ph.D. thesis, Universidad Complutense de Madrid, 380pp. (in Spanish).

Pérez-López, R., Muñoz-Martín, A., Paredes, C., de Vicente, G., Elorza, F.J., 2000. Dimensión fractal de la distribución espacial de fracturas en el área granítica de El Berrocal (Sistema Central): relación con el tensor de esfuerzos. Revista de la Sociedad Geológica de España 13, 487-503 (in Spanish).

Reches, Z., 1987. Determination of the tectonic stress from slip along faults that obey the Coulomb yield condition. Tectonics 7, 849-861.

Reches, Z., 1992. Constraints of the strength of the upper crust from stress inversion of fault slip data. Journal of Geophysical Research 97, 1248112493.

Rodríguez-Pascua, M.A., De Vicente, G., Calvo, J.P., Pérez-López, R., 2003. Similarities between recent seismic activity and paleoseismites during the Late Miocene in the external Betic belt (Spain): relationship by "b" value and the fractal dimension. Journal of Structural Geology $25,749-763$.

Scholz, C.H., Cowie, P., 1990. Determination of total strain from faulting using slip measurements. Nature 346, 837-839.

Vegas, R., Vázquez, J.T., Suriñacs, E., Marcos-González, A., 1990. Model of distributed deformation, block rotation and crystal thickening for the formation of the Spanish Central System. Tectonophysics 184, 367378.

Velde, B., Dubois, J., Touchard, G., Badri, A., 1990. Fractal analysis of fractures in rocks: the Cantor's Dust. Tectonophysics 179, 345-352.

Volland, S., Kruhl, J.H., 2004. Anisotropy quantification: the application of fractal geometry methods on tectonic fracture patterns of a Hercynian fault zone in NW-Sardinia. Journal of Structural Geology 26, 14891500 .

Walsh, J.J., Watterson, J., 1993. Fractal analysis of fracture patterns using the standard box-counting technique: valid and invalid methodologies. Journal of Structural Geology 15, 1509-1512. 